\title{
Does Green Technology Espousal Really Matter?
}

\author{
Dileep Kumar M. ${ }^{1}$ \& Ruswiati Surya Saputra ${ }^{1}$ \\ ${ }^{1}$ Othman Yeop Abdullah Graduate School of Business, Universiti Utara Malaysia, Sintok, Malaysia \\ Correspondence: Dileep Kumar M., Othman Yeop Abdullah Graduate School of Business, Universiti Utara \\ Malaysia, Sintok, Malaysia. Tel: 60-17-415-2541. E-mail: dileep@uum.edu.my
}

Received: February 20, 2014 Accepted: April 6, 2014 Online Published: May 30, 2014

doi:10.5539/ass.v10n11p66

URL: http://dx.doi.org/10.5539/ass.v10n11p66

\begin{abstract}
There is immense pressure across the world to adopt green technology and green practices in order to reduce the pollution level of urban and cosmopolitan areas. While, the adoption of green technology depends on several social and relative factors, there was so reluctance on the part of many to adopt it. Contextualizing the area of concern to the Tuk-Tuk, drivers in the city of Bangkok, Thailand, a study was conducted to assess the factors influencing adoption of green technology. The study followed qualitative research initially to explore unique factors and then confirmed those factors through qualitative research. Factor analysis was conducted to analyze the reliability of the instruments and data collected from the "tuk tuk" drivers. Almost 176 auto drivers were interviewed (informally) with a structured schedule and data collected. To analyze this data, study followed statistical tools like correlation and regression. The results clearly indicate that socioeconomic factors which are moderated by the green technology factors that influence the "TukTuk" drivers intention 'not to go green', even though they have the keen interest towards environmental concerns.
\end{abstract}

Keywords: green technology issues, environment, "TukTuk", auto-rickshaw drivers, socioeconomic condition, urbanization and industrialization

\section{Introduction}

"Tuk Tuk" or auto rickshaws are the small, three-wheeled vehicle. The auto rickshaw that carries passengers from one place to another has developed widespread environmental concerns in developing countries. It is widely mentioned that auto rickshaws generate more pollution than most other forms of transportations. It is speculated that, higher the urbanization trend, especially in developing courtiers, that develops higher environmental pollution. The report of environmental scientist's indicates that auto rickshaws did little to reduce pollution because of their inefficient, two-stroke engines and lack of maintenance. This environmental concern extends true to great by many research reports. On the other hand, if we look upon a decision of 'ban' these kinds of motor vehicle in cities, it will directly affect commuters on one hand and the day-to-day sustenance of "Tuk Tuk" based drivers on the other hand, leading to more troubled condition of poverty and unemployment. As a measure of it, government and environmental ministries are trying to convert the "Tuk Tuk", into CNG and thereby trying their level best to ensure a less polluted environment in cities, especially Bangkok city. Unfortunately, the "Tuk Tuk" drivers are not ready to accept this change due to countless reasons. Beyond technical reasons, the socio-demographic factors are well correlated with their resistance to change towards going green. This research paper tries to correlate the socio-demographic factors influence on "Tuk Tuk" drivers in Bangkok, Thailand, in their intention to go with green technology further with adoption of green attitude.

\section{Literature Review}

\subsection{Demographic Issues}

Urbanization is a phenomenon that has brought opportunities as well as challenges to Thailand economy. Bangkok, the capital of Thailand, has experienced a high rate of growth in recent years, including a high rate of in-migration. The projected population of the Bangkok mega-urban region in 2010 is 17.3 million, with the major share of the population increase coming from migration (Douglass, 1995).

Bangkok has gained the reputation of having among the most rapidly degraded and severely deteriorated urban environments in the world (Danced, 1996). Air pollution from particulates and lead, surface water pollution due to microbiological contamination, and traffic congestion are among Bangkok's most serious urban environmental problems (Ard-Am, 1997). 
Bangkok's industrialization is an important 'pull factor' for rural- urban migration. The 'push factor' is the declining standard of living in rural areas since the 1960s. The input of the agricultural sector to the Thai GDP has declined from $39.8 \%$ in 1960 to $12.4 \%$ in 1990, while the industrial sector contribution has increased from 18.2 per cent in 1960 to 39.2 per cent in 1990. The rural poor migrate to Bangkok for job opportunities, but most become the urban poor as they accept low wages due to a lack of knowledge and skills. Slums and squatter settlements are often the only places where they can afford to live (Douglass, 1995).

\subsection{Auto Rickshaw or TukTuk}

The "rickshaw" is a known vehicle around the world. The rickshaw is, being a small-scale local means of Vehicle. It is a human-powered vehicle for hire, usually with one or two seats for carrying passengers in addition to the driver. The TukTuk finds its origin in both the hand-drawn rickshaws of Japan and China as well as the highly functional Piaggio Ape of Italy. Tuk Tuk is known around the world for their highly effective means of transporting people from one location to another. For the past 60 years the TukTuk has been spreading, evolving, and morphing into one of the most important forms of ground transportation in the world. With the introduction of simple engines, TukTuks were birthed using 2-stroke engines, making a uniquely identifiable "tuktuk" (pronounced "toook-tooook") sound, thus their early given name. Due to their stylistic simplicity, demonstrated flexibility, and inexpensive operational cost, TukTuks fast became popular in transporting people and products in countless cultures and nations. This unequalled growth has persisted even until today as more and more countries give usage to the TukTuk. Just for a matter of perspective, there are presently more than 9 million in use in Thailand, 3 million in India, and 600,000 in Egypt. They are fast becoming common place on the streets of European, Mediterranean, Central American, and South American countries far and wide (TukTuk transport, 2012).

\subsection{Issues on Going with Green Technology}

An alternative solution to petroleum was found to run our automobiles during the year 2000, which are Compressed Natural Gas also known as CNG. CNG revolutionized the transportation system (Quaium, 2009). When, rickshaw companies have come out with alternative models such as Compressed Natural Gas Liquefied, Petroleum Gas (LPG) etc., the rickshaws started engaging in mitigating the pollution problem caused by traditional petrol models (Rajkumar, 1999).

Technical experts have suggested the use of $\mathrm{CNG}$ as an alternative fuel for automobiles. They have estimated that apart from being less hazardous, it is also environmentally friendly, can help in reducing the levels of pollutant emissions and is quite cost effective (Sruthijith, 2000). Two main disadvantages exist with incorporating those technologies on the rickshaws: (1) oil is still added to the chamber in the two stroke configurations, which adds to the pollution, and (2) LPG and CNG are nonrenewable energy sources (Rajkumar, 1999).

Quaium (2009), while elucidating natural gas issues with economy crisis indicates that judging the above benefits of CNG one may conclude that, since CNG has made a positive impact on the economy and the environment there is no issue with running vehicles on CNG. However, CNG is a nonrenewable energy source and despite all the benefits, the use of CNG to run vehicles is not sustainable. Unfortunately, as most things in Bangladesh are done without a vision and without considering the long-term impacts, the government kept on providing licenses to start up CNG conversion shops and CNG refueling stations one after another. This has created a crisis for natural gas in the country. The demand for natural gas is now more than the amount of gas that is being produced.

Dinesh and Dunu (2003) in their study in auto rickshaw drivers and auto entrepreneurs indicate that the drivers find it difficult to maintain the $\mathrm{CNG}$ engine. Lot many complain has come out on the failures related to technical aspect. The research data indicates that the CNG engines are not adequately lubricated and it necessitate additional cooling requirement. Related to the practical difficulties the research report further indicates that due to the frequent problems in the chain, the oil consumption increases to as much as $800 \mathrm{ml}$ per day.

Vishal and Swagatham (2011), in their critical analysis indicates that the researchers had overlooked was the fact that many of the auto rickshaws ran on two-stroke engines. Along with other vehicles, these two-stroke auto-rickshaws were also converted to CNG gas-powered rickshaws. Two-stroke engines are powerful, considering their weight and size, but they fail to burn around one-third of the fuel injected into them. The unburned fuel was thus directly emitted into the air. These emissions contained high levels of methane, a major greenhouse gas, and high particulate matter, both very harmful. Thus, the upgrade did not help in reducing pollution. Instead, it contributed the same amount of pollution, but by emitting a different mixture of greenhouse gases.

Interrelated to the technical issues faced by the CNG auto drivers by Dinesh and Dunu (2003) further indicated that effect of absence of trained mechanics. This indicates that all the maintenance activities of the vehicle and the 
engines will be difficult task to the drivers. Add to this point, wherever the outlets are in need to support the maintenance activities there will be inordinate delays. Adding up, the cost of maintenances will be the result of such issues. The report further indicates that if the manufacturer cannot resolve these issues, then, the popularity of $\mathrm{CNG}$ as a fuel will get affected.

\subsection{Plight of Auto Rickshaw Drivers}

Rickshaw drivers (puller) are a marginalized community. Most rickshaw drivers cannot afford to buy their own rickshaws and rent them daily. In so doing, they pay the value of the asset, many times over in the course of their lives without ever owning it. With a lack of education and formal representation, they face harassment by the police and municipal officials as they go about their trade, and bribes, long queues and delays as they attempt to obtain official documentation, such as licenses, registration papers and insurance (Naveen Krishna, 2012).

Johnson and Rogaly, (1997) in their report indicate that besides the need for small business development, poor people need access to credit to cover unexpected events that create a sudden financial crisis. Examples include accidents and sickness, which can prevent people from going to work thus causing a crisis in providing food and shelter for families. Small loans are necessary to allow for the limited repayment ability - low wages clearly mean they are unable to save money for their welfare. Moreover, they cannot access the normal banking systems due to their lack of collateral. When a crisis occurs, they must borrow from local moneylenders who usually charge higher interest rates than formal bank rates given the risks when lending without physical collateral.

The above account thus lead us to believe that it will be a burden to the Tuk Tuk drivers if they cannot afford the green technology and technology maintenance cost. The situation will be more worthless if there will not be adequate support from the financial institutions. Many socio- demographic and green technology issues are leading to Tuk Tuk driver's intention to adopt green. This particular research tried to build up this research paper based on these above said parameters linking with the research objectives.

\section{Problem Formulation}

Auto rickshaw or "TukTuk" is an important means of transportation in many countries like Thailand, India, Indonesia, Bangladesh and many developing courtiers. Millions of people make use of Auto rickshaw or "TukTuk" as a basic means of transportation. While they ensure better means of transportation to the commuters, "TukTuk" creates high level environmental pollution in cities and towns. The rate of pollution has gone in parallel with the increased rate of urbanization and industrialization. Contextualizing the topic to Bangkok scenario, Thailand, the city has witnessed high rate of urbanization and correlated environmental pollution. As indicated above, the means of transportation, especially "TukTuk" also create a high level of environmental pollution. It is assumed in the research that though the city is gored with high rate of urbanization, the mindset of the people is lagging behind in going green. It is reported that when it comes to green issues, legislation only has played their role at limited level so far. Attitude of people too must go 'in Toto' with the changing scenario, but unfortunately, it has not witnessed. Many crucial factors, which influence the attitude of people, especially on "TukTuk" drivers, in their attitude towards green adoption, starts from their socio-economic condition to the green technology issues. Hence, contemporarily it is necessary to understand why these "TukTuk" drivers are not going with CNG or alternative fuel based transport system that reduce the environmental pollution to a great extent.

\section{Statement of the Problem}

Considering the issues related to the adoption of green technology among the Tuk Tuk Drivers in Thailand, this particular research focuses on "Does Green Technology Espousal Really Matter?

\section{Research Objectives}

This research seeks to achieve the following objectives:

1) To analyze significant relationship between socio-demographic factors and going green attitude of TukTuk drivers in Thailand.

2) To analyze significant influence of socio-demographic factors on going green attitude of TukTuk drivers in Thailand.

3) To ascertain mediating effect of green technology issues on going green attitude of TukTuk drivers in Thailand.

\section{Research Hypotheses}

H1: There may have significant relationship between socio-demographic factors and going green attitude of TukTuk drivers in Thailand.

H2: The socio-demographic factors may have significant influence on going green attitude of TukTuk drivers in 


\section{Thailand.}

H3: The green technology issues may have a significant mediating effect on going green attitude of TukTuk drivers in Thailand.

\section{Research Framework}

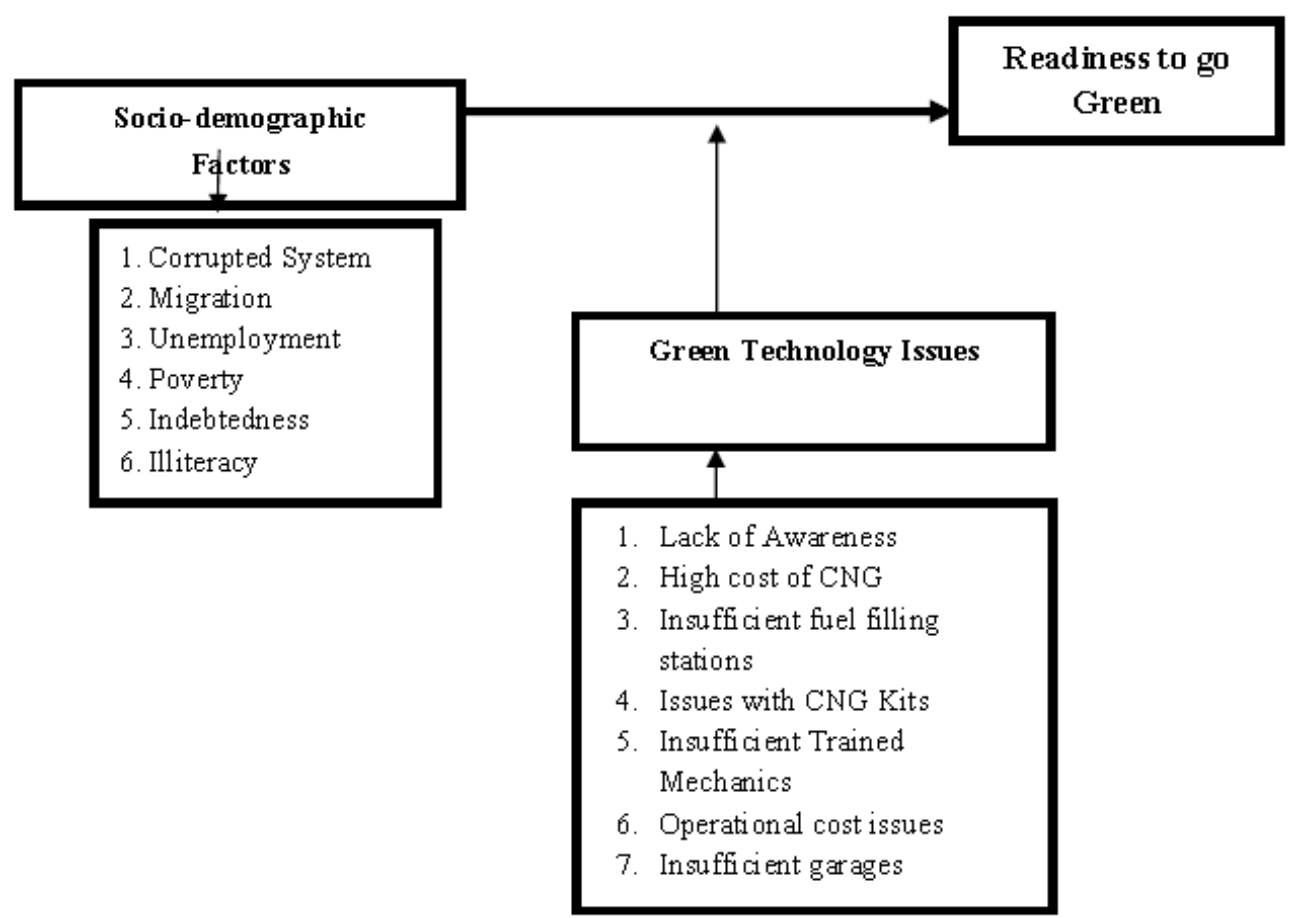

Figure 1. Research framework

\section{Conceptual Definitions}

Green: In this particular research 'green' means the environmental consciousness people with positive environmental attributes or objectives.

Going Green: 'Going green' which reflect the attitude of people towards using various methods to neutralize the effects of global warming and learning about the environment for being proofing one against future human issues

\section{Green Technology:}

Green technology in this particular research refers to the production, development and application of products, equipment and systems used to conserve the natural environment and resources that is more environmentally friendly or that is considered less harmful than technologies that are more traditional which minimize and reduces the negative impact of human activities.

Socio-demographic: In this particular research 'green' means the effect of migration, population, illiteracy, indebtedness, corruption, unemployment and poverty.

\section{TukTuk}

"TukTuk" or auto rickshaws are smaller, three-wheeled vehicle, the auto rickshaw that moves small loads of carries passengers from one place to another

\section{Methodology}

\subsection{Population}

Bangkok is considered as a city affected by the effect of urbanization and industrialization. More number of motor vehicles and means of transportation have created heavy environmental pollution in the city. Considering the expansion of the cities, the number of vehicles also increased. Adopting green technology is a solution to high pollution in cities. Related to this scenario "TukTuk" three wheeler vehicles also have a tremendous role in 
air pollution. Hence, the study includes the "TukTuk" three wheeler drivers in the Bangkok city as the population of the research.

\subsection{Research Design}

In order to conduct this research an exploratory approach was initially designed in consultation with 'TukTuk' driver's in order to obtain information on issues related to going green. Soon after identifying the variables related to going green and social-demographic factors, the study adopted descriptive study design, since it is more about fact-finding methodology.

\subsection{Sampling}

The respondents of the sample were the 'TukTuk' drivers, taken randomly from Bangkok city considering their age, program or state of origin. It is identified that the majority is migrated population from the rural areas of Thailand. Considering the equal representation from each region, the study follows proportionate probabilistic sampling size as its sampling method. The study concentrates only on male 'TukTuk' drivers and they belong to an age group of 18-40. 176 'TukTuk' drivers were finally considered for the study considering the representative sample size.

\subsection{Tools of Data Collection}

The research will consider following tools for the data collection.

1) Questionnaire on Socio-demographic dimension.

2) Questionnaire on Going Green

3) Questionnaire on Green Technology Issues (moderating variable).

\subsection{Validity and Reliability}

Validity is the ability of a tool to measure what is supposed to measure. The validity of an instrument is the degree to which an instrument measures what it is intended to measure (Polit \& Hungler, 1993). Validity tests, then compare and measure the concept that a researcher supposed measure with its accuracy. Precisely the degree to which an instrument used by the researcher measures what he/she intended to measure. It was expected that the instrument should ensure content, construct and face validity.

\subsubsection{Content Validity}

The objective of this phase was to get the agreements of experts on the concept, constructs and content of the items selected in the three draft questionnaire'. To get the content validity, in addition to the literature review, the study was incorporated triangulation method of qualitative research

\subsubsection{Face Validity}

The study further ensured face validity by examining the instrument looks as though it is measuring what it was supposed to measure. Face validity is a necessary procedure in any instrument development process (Benson \& Clark 1983). To get the face validity, experts in the field of management areas, statisticians, and academicians were contacted into. Thus the experts in the field of management and human resources areas, statisticians, and academicians were cross verified the face validity of the instrument. To end with, the construction of the items based on the concepts of the constructs, sub-constructs that developed out of the literature review and case interviews, was made.

\subsubsection{Construct Validity}

To test the construct validity the instrument is well correlated to the underpinning theories, which were closely knit with the socio-demographic factors, green technological factors and individual factors, in relation to the three questionnaires were made. Validation of the instruments were done on factors related to socio-demographic factors, green technological factors and individual factors.

\subsection{Factor Analysis and Reliability Test}

Prior to any validity and reliability tests, the tests of assumptions for multivariate analysis will be conducted to ensure that the data met the normality, linearity, multicollinearity, and homoscedasticity assumptions. The next important step in data analysis is to understand the dimension of the variables in the proposed framework or relationships posited in empirical research (Hair et al., 2010). In other words, factor analysis should be performed to identify the structure of interrelationship among a large number of items in the study. This may be done by defining common underlying dimensions, commonly known as factor (Hair et al., 2010). The dimensions of the scale were examined by factor analyzing the items using the principal components analysis 
with Varimax rotation. Minimum eigenvalues of 1.0 helped determine the number of factors or dimensions for each scale (Hair et al., 2010). Although factor loadings of .30 to 0.40 are considered acceptable, however, factor loadings greater than 0.50 are generally necessary for the practical significance (Hair et al., 2010). Hence, the items for a factor will be retained only when the absolute size of their factor loading is above 0.50 .

To test the internal consistency of the measurement, reliability analysis is performed on the factors extracted using the benchmark suggested by Nunnally (1978). Generally, the closer reliability score gets to 1.0, the more reliable the scale would be. According to Nunnally (1978), the reliability score of.70 and above is acceptable and those above. 80 are considered good. As noted by Peter (1979), reliability scores that less than .60 is still considered acceptable for social science studies. Following the literature, a reliability score of.70 is used as the benchmark for this study. It should be noted that all the negatively worded items in the questionnaire were first being reversed coded prior to the reliability test. In the case of coefficient alpha value is smaller than.70, the item with the lowest corrected item-to-total correlation is removed until then.70 levels are met (Pallant, 2001).

Table 1. Factor analysis: socio-demographic factors

\begin{tabular}{clcc}
\hline SI No & \multicolumn{1}{c}{ Factors } & \% of variance explained & Cronbach $\boldsymbol{\alpha}$ \\
\hline 1 & Corrupted System & 0.4992 & 0.812 \\
2 & Migration & 0.6110 & 0.800 \\
3 & Unemployment & 0.4712 & 0.803 \\
4 & Poverty & 0.3010 & 0.819 \\
5 & Indebtedness & 0.6001 & 0.830 \\
6 & Illiteracy & 0.5856 & 0.826 \\
\hline
\end{tabular}

Table 1 indicates the results of factor analysis on social demographic factors. The entire factors (F1, F2, F3, F4, F5, and F6, that included in the factor analysis were found most important in explaining $(0.4992,0.6110,0$. $4712,0.3010,0.6001$, and 0.5856$)$ the variance respectively. Based on the results, all the factors are there by selected for further analysis.

Table 2. Factor analysis: green technology issues

\begin{tabular}{clcc}
\hline SI No & \multicolumn{1}{c}{ Factors } & \% of variance explained & Cronbach $\boldsymbol{\alpha}$ \\
\hline $\mathbf{1}$ & Lack of awareness & 0.3899 & 0.790 \\
$\mathbf{2}$ & High cost of CNG "TukTuk" & 0.4190 & 0.841 \\
$\mathbf{3}$ & Insufficient fuel filling stations & 0.4001 & 0.806 \\
$\mathbf{4}$ & Issues with CNG kits & 0.5221 & 0.811 \\
$\mathbf{5}$ & Insufficient trained mechanics & 0.6231 & 0.800 \\
$\mathbf{6}$ & Operational cost issues & 0.4996 & 0.832 \\
$\mathbf{7}$ & Insufficient garages & 0.5010 & 0.844 \\
\hline
\end{tabular}

Table 2 indicates the results of factor analysis on green technology issues factors. The entire factors (F1, F2, F3, F4, F5, F6 and F7, that included in the factor analysis were found most important in explaining $(0.3899,0.4190$, $0.4712,0.5221,0.6231,0.4996$ and 0.6231$)$ the variance respectively. Based on the results, all the factors are there by selected for further analysis.

Table 3. Reliability test: going green

\begin{tabular}{cccc}
\hline SI No & Factor & \% of variance explained & Cronbach $\boldsymbol{\alpha}$ \\
\hline 1 & Going Green & 0.5122 & 0.809 \\
\hline
\end{tabular}


Reliability test was conducted on the dependent variables, going green attitude of "TukTuk" drivers (table no 3). The Cronbach's alpha values of the study variables are shown in the table. As a result, Cronbach's alpha for the going green attitude (0.809) considered for the study.

\subsection{Ethical Considerations}

In both the phases, the ethical considerations were well followed by the researches due to the sensitive issues related to the topic. This sensitivity is perceived from a Tuk Tuk driver's perspective. Drivers sought to ensure their anonymity during all stages of research. The drivers were assured that the summary data would be disseminated to the management, but in no way the responses of them can be identified. It is also assured that the data will be destroyed keeping the documents after a reasonable period. Instead of the names of the drivers the data coded with numbers to ensure the anonymity both in case studies as well as quantitative data collection procedures.

\subsection{Data Collection}

Data collection was done based on the three instruments specifically developed for this study. The researchers assured the confidentiality of the data to all "tuktuk" drivers who responded in this research. "Tuktuk" drivers of different locale of Bangkok city were approached initially for responses. Out of which 246 respondents cross-checked the confidentiality of information to the researcher and finally 176 were provided the information related to the topic selected. The researchers assured cent-percent confidentiality to the driver's in order to get an appropriate response from them considering the sensitivity of data.

\subsection{Analysis and Results}

The data collected were analyzed based on descriptive statistics, correlation, and regression Test. SPSS $19^{\text {th }}$ version was used to analyze the data collected. The details of the analysis are given below.

Table 4. Correlation Analysis: Socio-demographic factors on going green

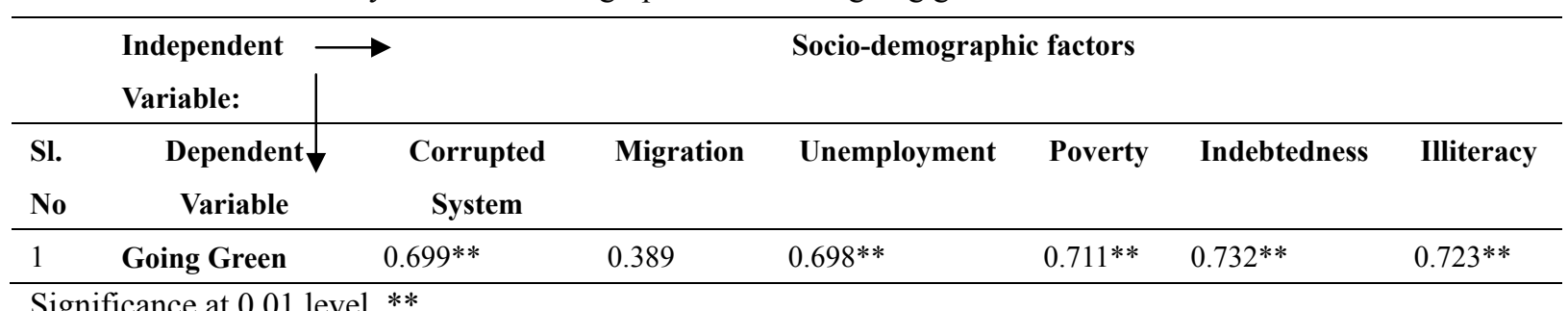

Significance at 0.01 level, $* *$

The first hypothesis (H1) indicates, "there may have significant relationship between socio-demographic factors and going green attitude of TukTuk drivers in Thailand." The findings of the table no (4) clearly shows that all the sub variables of independent variable, socio-demographic factors [corrupted system $\left(0.699^{* *}\right)$, unemployment $(0.698)$, poverty $\left(0.711^{* *}\right)$, indebtedness $\left(0.732^{* *}\right)$ and illiteracy $\left.\left(0.723^{* *}\right)\right]$ except migration, are significantly correlated to dependent variable $(\mathrm{p}=0.01$ level $)$ going green. This indicates that the socio-demographic factors are significantly related to going green attitude of "TukTuk" drivers in Thailand, (significant at 0.01 levels). The sub variable (of the independent variable) migration (0.399) is not related to going green attitude of "TukTuk drivers in this research. Since majority variable having inter-correlation, the study accepts the first hypothesis selected for the research.

Table 5. Regression Analysis: Socio-demographic factors on going green

\begin{tabular}{|c|c|c|c|c|c|c|c|c|}
\hline \multicolumn{2}{|c|}{$\begin{array}{c}\text { Independent } \\
\text { Variable: } \\
\end{array}$} & \multicolumn{6}{|c|}{ Socio-demographic factors } & \multirow{2}{*}{$\begin{array}{c}\text { Adjusted } \\
\text { R2 }\end{array}$} \\
\hline $\begin{array}{l}\text { Sl. } \\
\text { No }\end{array}$ & $\begin{array}{c}\text { Dependent } \\
\text { Variable }\end{array}$ & $\begin{array}{c}\text { Corrupted } \\
\text { System }\end{array}$ & Migration & Unemployment & Poverty & Indebtedness & Illiteracy & \\
\hline 1 & Going Green & $0.318 * *$ & 0.267 & $0.422 * *$ & $0.432 * *$ & $0.398 * *$ & $0.410 * *$ & 0.21 \\
\hline
\end{tabular}

Significance at 0.01 levels, ** 
The major hypothesis stated includes (H2) "The socio-demographic factors may have significant influence on going green attitude of TukTuk drivers in Thailand". Multiple regression analysis (table no. 5) used for examining whether socio-demographic factors (6) dimension is affected by going-green attitude of drivers. The findings of the table no (1) clearly show that the going green attitude of "TukTuk drivers" are influenced by five sub variables of independent variable, socio-demographic factor [corrupted system $\left(0.318^{* *}\right)$, unemployment $(0.422)$, poverty $\left(0.432^{* *}\right)$, indebtedness $\left(0.398^{* *}\right)$ and illiteracy $\left(0.410^{* *}\right)$ at $\mathrm{p}=0.01$ levels.] The coefficient is substantial, positive and significant (standardized coefficient 0.21 , significant at 0.001 ). The results show insignificant influence of migration ongoing-green attitude (0.267). The finding is in support of Hypothesis 2 that proposed a significant influence of socio-demographic factors on going green attitude of TukTuk drivers in Thailand.

Table 6. Moderating effect of green technology issues

\begin{tabular}{ccc}
\hline Going Green & $\begin{array}{c}\text { Beta coefficient without going green } \\
\text { (Model 1) }\end{array}$ & $\begin{array}{c}\text { Beta coefficient with going green } \\
\text { (Model 2) }\end{array}$ \\
\hline \multirow{2}{*}{ Green Technology } & $.280^{* *}$ & -.060 \\
issues & $\mathrm{R} 2=.081$ & $\mathrm{R} 2=.193$ \\
& Adjusted $\mathrm{R} 2=.070$ & Adjusted $\mathrm{R} 2=.177$ \\
\hline
\end{tabular}

To verify the mediation effect of Green Technology Issues in the relationship between social-demographic factors and going green, another regression analysis, that hierarchically regressed going green (step 1), and not going green (step 2) was conducted. Summary of the results are in Table 6.

The beta coefficient for model 1 is significantly higher than that of model 2. Coupled with the increase in Adjusted R2 with .107 (i.e. .177 - .070) explain the mediation effect of green technology issues on the relationship between socio-demographic factors - going green. There is therefore an indirect positive relationship between socio-demographic factors - going green via green technology issues.

\subsection{Discussion}

The major objective of the current research was to explore the relationship between socio-demographic factors and going green attitude of "tuk tuk" drivers in Bangkok city of Thailand and thereby analyze the significant influence of the independent variable on dependent variables selected for the study. The study showed significant positive relation between socio-demographic factors and going green attitude of "tuk tuk" drivers in. In relation to going green issues as moderating factors, the results show that the green technology issues are having a high moderating effect on going green attitude of "tuk tuk" drivers. The results of the study are further discussed in detail below.

Major socio-demographic sub variables considered for this study is corrupted system unemployment, poverty indebtedness, illiteracy and migration in relation to going green attitude of "tuk tuk" drivers. The findings well correlated with all the factors that except one factor viz., migration. Rest all other factors is well correlated with the dependent variable, 'going green attitude' of the "tuk tuk" drivers in Bangkok. The study clearly indicates that the "tuk tuk" drivers do not want to go with green at rickshaws because of their high level of poverty, unemployment, indebtedness, corrupted system and illiteracy. Among the major factors identified in this research, poverty and unemployment was closely correlated with their decision of not going with green technology.

Explain the socio-demographic features of Bangkok Tuk Tuk drivers higher rate of migration from rural areas, Douglass (1995) stated that Bangkok, the capital of Thailand, has experienced a high rate of growth in recent years, including a high rate of in-migration. In correlation with the population explosion, the level of unemployment and poverty has also increased in alarming proportion. In the rural areas of Thailand, the level of poverty is very high and they are unable to meet the two ends of the month. In the rural areas, people have fewer employment opportunities and they were finding difficult to maintain their family sustenance. People migrate from the interior rural areas for employment and finally settled as "tuk tuk" drivers in the Bangkok city. The city small entrepreneurs has provided them with the job as auto rickshaw drivers. The poverty level is not much different in city life also, compared to rural areas, but the availability of job as "tuk tuk" drivers, to a great extent supported them to live and leave with limited savings.

It is well pointed out by the "tuk tuk" drivers that they are unable to meet the "green auto rickshaw cost and maintenance cost' as they feel the modern green auto rickshaws are very much 'expensive' in the midst of an 
acute level of poverty. The finding to be discussed in relation to the moderating effect of green technology issues and it is well substantiated the above discussion that the financial condition of the "tuk tuk" drivers didn't match up with them to appreciate going green option. The findings of the moderating effect of green technology issues well pointed out that the factors like Lack of awareness, High cost of CNG "Tuk Tuk", Insufficient fuel filling stations, Issues with CNG kits, Operational cost issues, and Insufficient garages are having a high effect on their decision to go green. The cost of owning the vehicle including the permit, etc., is much higher than the official sale price of the vehicle because of the agents and intermediaries involved. Officially, at present, the chassis cost Rs 97,000 while the insurance, taxes, meter, etc., cost another Rs 10,000. However, the actual price paid by the TSR owner to the financier is as much as Rs 1, 80,000 (Dinesh and Dunu, 2003).

The interaction effect of the moderating variable indicates that the issue of going green was not only related to their socioeconomic condition, but also related to technological and operational issues. A combined effect of socio-demographic factors and green technology operational issues observed as the main factor behind their lack of interest towards going green. If we refer, the past findings related to green technology issues that met by the green auto rickshaw drivers in many cities across the countries that the drivers are facing problems related to CNG engines. Dinesh and Dunu, (2003), in their study in auto rickshaw drivers and auto entrepreneurs clearly indicates that majority drivers find it is difficult and expensive to maintain the CNG engine as compared to the petrol engine. A third of the drivers complained of technical failures and difficulties in having vehicles repaired. Almost these findings are replicated in this Bangkok study also. It is observed by the "tuk tuk" drivers that the operational cost is much higher compared to traditional auto rickshaws.

Though the city of Bangkok has grown up with massive levels in population and transportation, the "tuk tuk" drivers pointed out the fact that there are insufficient fuel filling stations and insufficient garages, in correlation with that, to meet the requirement of green auto rickshaws. The findings pointed out that even in the midst of difficulties, the "tuk tuk" drivers are thinking about going green but, technicians having adequate knowledge to handle the issues related to $\mathrm{CNG}$ auto rickshaws. The Major consequence of lack of adequate number of garages is the excessive delay in getting through company garage. Neither the traditional auto rickshaw garage technicians can attend to the issues of green auto rickshaw problems nor the drivers of green auto rickshaws can get speedy attention and repair from the company garage. Substantiating the technical issues faced by the CNG auto drivers, Dinesh and Dunu (2003) further report because of the absence of trained mechanics, all repairs have to be in company garages and there are inordinate delays in these outlets. The cost of company-based repair found much higher compared to the local technicians and the repair of traditional auto rickshaws. The cost of traditional auto rickshaws is much less and it is affordable to the "tuk tuk" drivers considering their socioeconomic conditions. The maintenance cost of green auto rickshaws is much higher for green auto rickshaws compared to traditional auto rickshaws. The same observation is reported in many countries like India and Bangladesh.

Contributing to the present moderating effect, the socio-demographic factor illiteracy also influencing "tuk tuk" driver's decision to go green. The company garages are taking advantage of the lack of awareness of the technical side of the green auto rickshaws, and charging more on the repair of their vehicles. The auto drivers"tuk tuk" drivers indicate that they are exploited by the company garages with the high cost of repair, which is affordable to them. Because of that they prefer local technicians and traditional auto rickshaws rather than green auto rickshaws.

The most important factor here in this context to be discussed is the corruption factor. The "tuk tuk" drivers have such a complaint on the system that the corruption is prevailed in all areas where they have to get support to go green. They have to bribe the office to get loans and the bank officers get the loan top be passed and such tasks are hilarious to accept it considering their socioeconomic condition. Almost similar findings were observed in the past supporting the corrupt practices in Thailand. According to the perception indicators surveyed by the IMD, corruption and bribery remain widespread in Thailand. These indicators show that the Thai civil service operates in an environment where corruption and bribery are rampant and where bureaucracy is subject to considerable political influence.

\subsection{Implication}

The study well pointed out the fact that socio-demographic factors having major effect and green technology issues factors having high moderating effect on the "tuk tuk" auto rickshaw driver's decision "not to go with green vehicle'. Though the study observed many factors influence on Tuk Tuk driver's decision 'not to go with green technology'. The poverty-ridden life and unemployment, have found to be the major socio-demographic factors major factors that influence more on Tuk Tuk drivers unfavorable. Their decision also related to poor 
monitory capacity and the low-level system administration support. The drivers do not have the capacity to purchase the vehicle, with their poverty-ridden life, and they are not in a position to address the green technology issues. Operational issues like lack of adequate number of garages and the technicians, high cost of CNG kits etc. also influenced their motivation level. To go with green technology vehicle the thrust should give also to the existing administrative system of Thailand. The findings thus well pointed out the fact that the corrupted system has also made it difficult to "tuk tuk" auto rickshaw drivers to get appropriate financial support from the authorities, This scenario intern de-motivate them not to to buy CNG based auto rickshaws. Though the green vehicle reduces the expenditure as well as the pollution level, the "tuk tuk" auto rickshaw driver's lack of awareness of its benefits also influenced their decision "not to go green. The conglomerate effect of socio-demographic factors and green technology issues thus contribute "tuk tuk" auto rickshaw driver's decision 'not to buy green auto rickshaws'. The outcome of their decision has severe consequences like high level of pollution in Bangkok city.

\section{Conclusion}

This particular research focused on the effect of socio-demographic factors influence on "Tuk Tuk" driver's decision 'not to go with green vehicle'. The study clearly pointed out the effect of the dependent variable on independent variables. It has well pointed out in the discussion and implication part of this research that the 'financial constraints of life' as the major factor that influence auto driver's decision not to go with green vehicle. The financial constraints need to be well correlated to green technology adoption behaviour. The major contribution of this research is the findings related to moderating variable, green technology issues influence on decision 'not to with green vehicle'. Though green technology issues considered as a separate influential component, its influence did close knit with the financial constraints. The operational cost, maintenance cost, cost of CNG kit etc., like factors having a high influence on "Tuk Tuk" driver's decision not to with green vehicle. The "Tuk Tuk" drivers expect that the administrative system and banking system should support them in getting the appropriate financial support that helps them to purchase 'green vehicles'. However, the study observed influence of high corruption of system authorities, which intern de-motivate them not to go with green auto rickshaws. The study thus indicates that "going green attitude" is a "tough decision from the viewpoint of "Tuk Tuk" drivers. The study envisages more effort from the system authorities, that may support these migrated auto drivers in getting right financial assistance, removing all the administrative difficulties, for accessing financial sources, which may contribute best to reduction of environmental issues (emission of Carbone monoxide from various vehicles) issues of Thailand. In this research, the researchers considered only city of Bangkok. More research, incorporating other areas of Thailand also need to be conducted to get generalizable findings.

\section{Acknowledgement}

This research paper has its origin from the research project supported by Othman Yeop Abdullah Graduate School of Business (OYAGSB), Universiti Utara Malaysia, Sintok, Kedah, Malaysia. The researchers express their sincere gratitude to the Dean of OYAGSB, on his constant support in the accomplishment of this project further its dissemination to the research and academic world to get its wider applicability.

\section{References}

Ard-am, O., \& Soonthorndhada, K. (1997). Household Economy and Environmental Management in Bangkok: The Cases of Wat Chonglom and Yen-ar-kard (II). Bangkok: Mahidol University.

Benson, J., \& Clark, F. (1983). A guide for instrument development and validation. American Journal of Occupational Therapy, 36, 789-800. http://dx.doi.org/10.5014/ajot.36.12.789

Danced. (1996). Urban Environmental Management in Thailand - A Strategic Planning Process. Bangkok: NESDB/DANCED.

Dinesh, M., \& Dunu, R. (2003, January 18). Operating on Three Wheels: Auto-Rickshaw Drivers of Delhi. Economic and Political Weekly.

Douglass, M. (1995). Global interdependence and urbanization: Planning for the BangkokMega-Urban Region. In T. G. McGee, \& I. M. Robinson (Eds.), The Mega-Urban Regions of Southeast Asia (pp. 63). Vancouver: UBC Press.

Hair, J. F., Black, W. C., Babin, B. J., \& Anderson, R. E. (2010). Multivariate Data Analysis (7th ed.). Prentice Hall.

Johnson, S., \& Regally, B. (1997). Microfinance and Poverty Reduction. United Kingdom: Oxfam. 
Naveen, K. (2012). Converting poor to power. Retrieved February 20, 2012, from $\mathrm{http}: /$ dasra.org/n/forwebsite/dasra/Reports /SMV\%20Wheels.pdf

Nunnally, J. C. (1978). Psychometric theory (2nd ed.) New York: McGraw-Hill.

Pallant, J. (2001). The SPSS survival manual: A step-by-step guide to data analysis using SPSS for Windows (10th ed.). St Leonards, NSW: Allen \& Unwin, Palo Alto, CA: Consulting Psychologist Press.

Rajkumar, P. (1999). Effect of air pollution on respiratory system of auto rickshaw drivers in Delhi, Indian Journal of Occupation and Environmental Medicine, 3(4), 171-173.

Sruthijith, K. K. (2000). CNG: Environmentalism vs. Economics, Centre for Civil Society. Retrieved February 20, 2012, from http://ccs.in/ccsindia/policy/enviro/studies/wp0034.pdf

TukTuk transport. (2012). What's a TukTuk? American made all electric, earth-friendly tuktuk!

Vishal, S. (2011). India's CNG Experiment for Curbing Air Pollution. Retrieved February 20, 2012, from http://www.brighthub.com/environment/renewable-energy/articles/120554.aspx

\section{Copyrights}

Copyright for this article is retained by the author(s), with first publication rights granted to the journal.

This is an open-access article distributed under the terms and conditions of the Creative Commons Attribution license (http://creativecommons.org/licenses/by/3.0/). 